\title{
Crisis Communication During the Ebola Outbreak in West Africa: The Paradoxes of Decontextualized Contextualization
}

\author{
Loïs Bastide
}

\begin{abstract}
As organizations involved in the 2014-2016 Ebola virus disease (EVD) outbreak response in West Africa are now drawing lessons from the crisis, the "manufacture of consent" (Burawoy 1979) emerges as an important issue. Recommendations and public health interventions developed during the response were met with suspicion and often resistances by affected populations, pushing involved organizations and actors to reflect about the validity of their risk communication tools and concepts. These difficulties stressed the numerous shortcomings of risk communication practices, which proved inefficient in an unfamiliar social and cultural context. Many reasons can be pointed-out to explain this failure to communicate risks and public health measures effectively under these circumstances. They include: unrealistic goals for communication; lack of integration of social science skills and knowledge in communication guidelines and human resources; underestimation of the breadth of communication-related tasks; over-segmentation and lack of clarity of communication concepts and expertise (risk communication, crisis communication, social mobilization, and health promotion are all but a few of these categories). Among all these possible lines of inquiry, I want to address what can arguably be considered the most fundamental flaw of crisis communication during the West African EVD episode: its inability to take into account and analyze efficiently the context of the intervention.
\end{abstract}

Keywords Ebola • Public health interventions - Risk communication Social mobilization

\footnotetext{
L. Bastide $(\square)$

Institute of Sociological Research, University of Geneva, Geneva, Switzerland e-mail: lois.bastide@unige.ch 


\section{Introduction}

As organizations involved in the 2014-2016 Ebola virus disease (EVD) outbreak response in West Africa are now drawing lessons from the crisis, the "manufacture of consent" (Burawoy 1979) emerges as an important issue. Recommendations and public health interventions developed during the response were met with suspicion and often resistances by affected populations (Fribault 2015), pushing involved organizations and actors to reflect about the validity of their risk communication tools and concepts. These difficulties stressed the numerous shortcomings of risk communication practices, which proved inefficient in an unfamiliar social and cultural context.

Many reasons can be pointed-out to explain this failure to communicate risks and public health measures effectively under these circumstances. They include: unrealistic goals for communication; lack of integration of social science skills and knowledge in communication guidelines and human resources; underestimation of the breadth of communication-related tasks; over-segmentation and lack of clarity of communication concepts and expertise (risk communication, crisis communication, social mobilization, and health promotion are all but a few of these categories). Among all these possible lines of inquiry, I want to address what can arguably be considered the most fundamental flaw of crisis communication during the West African EVD episode: its inability to take into account and analyze efficiently the context of the intervention.

To discuss this point, I will start by proposing an informed definition - to the extent that social sciences are concerned — of what a "context" might be. Drawing on this definition, I will then extract a few significant characteristics of the response context, by applying proper analytical tools assembled from the disciplinary archives of social sciences (thus, showing that the issue is more about heuristics than knowledge of local circumstances per se). In the last section, I will contrast this analytical framework with the techniques of inquiry available to health emergency communication experts. These tools and related practices were identified and investigated during different fieldworks involving interviews with risk communication experts at the World Health Organization (WHO) and at the US Centers for Disease Control and Prevention (CDCs), as well as observations at WHO's Department of Communications (DCO). ${ }^{1}$ This will allow to show that these

\footnotetext{
${ }^{1}$ Part of these fieldworks took place in the context of the Organizing, communicating and costing in risk governance: learning lessons beyond the H1N1 pandemic research project (2013-2017), funded by the Swiss National Science Foundation, with a core research team composed of scholars from the Department of Sociology, University of Geneva, and the Haute Ecole de Gestion, Geneva. Other observations and interviews were conducted in the context of a joint research project between the Department of Sociology, University of Geneva, and WHO's DCO, titled "Generating evidences by capturing field experience from WHO-led deployment of risk communication experts do West Africa" (2015).
} 
techniques tend to erase contexts by taking an individual, psychological and behavioral perspective on affected populations, in the spirit of Evidence-Based Medicine (Brives et al. 2016).

\section{Understanding "Context"}

Looking back as far as at Jakobson's famous scheme of the functions of language (1960), which identified the context as a pivotal determinant of human communication, it is striking to see how communication, as a professional domain and practice, has paid little attention to this very dimension. In this respect, the Ebola outbreak in West Africa certainly acted as a powerful reminder: Most of international responders did not understand where they stood during the first months of the response, thus falling in all sorts of traps and pitfalls, causing much delays in necessary interventions: Ebola patients escaped; families and communities hid their ills; dead bodies were silently buried (Faye 2015; Moulin 2015); international funds vanished in the maze of national and regional bureaucracies. Puzzled by these facts, a common reaction among responders was to attribute these failures to backward beliefs, in affected countries, and to a lack of rationality (personal interviews, WHO; for a media account see Malagardis 2014). This kind of stereotypes outlines the lack of understanding of local circumstances in West Africa. Dangerously, these assumptions often served as a base for the development of public health interventions.

As Simmel (2007) has shown, stereotyping is a basic social process: it is a cognitive strategy aiming at offsetting a lack of knowledge about unfamiliar interactional partners, at the beginning of a relationship. When encountering new "others", stereotypes facilitate interactions as they serve as a baseline to draw expectations and possible lines of conduct, thus structuring an incipient relationship. As the relationship unfolds, actual knowledge about interactional partners is gathered through recurring encounters. It then progressively substitutes the necessary but highly biased information encoded in the stereotype. This process of learning through interaction is obvious in the response to the Ebola crisis in West Africa. A good example is the idea of African people living in traditional communities rather than being constituted of highly mobile individuals. This pervasive social representation, permeated with primordialist assumptions, prevented understanding early enough that affected areas were crisscrossed by intense human circulations - rather than being composed of still, enclosed tribal entities-spreading the virus along roads, routes, and paths. This view also caused an underestimation of current political and economic dynamics across national borders. Realization that the concept of community was misplaced and might have had a problematic effect on the response slowly emerged as a result of actual experiences on the field, which proved the concept to be misleading. However, this understanding came late and it was just starting to develop as an emerging topic among the leading actors of the 
response when WHO started to engage in a process of after-action analysis in order to draw lessons from the crisis, in November $2015 .^{2}$

Rather than developing systematic analytical tools to investigate actual social and societal patterns in affected and "at risk" areas, responding institutions thus relied on such basic, lay social representations (stereotypes) to develop their actions, as no system was in place to gather and process the necessary information, not only in "real-time" but by tapping into existing knowledge on best-practices to deal with an Ebola outbreak (Bourrier forthcoming). This failure to analyze the social determinants of the crisis points toward a lack of understanding of contextualization, as a basic and pivotal building block of human communication (Winkin 2001). To analyze these difficulties, let me first outline a rudimentary conceptualization of what a "context" might be, as far as social sciences are concerned. By identifying relevant analytical tools, I will then be able to contrast a scientifically informed definition of contextualization process with the actual cognitive and communicative processes developed by responding institutions to characterize their field of operations.

Speaking of contextualization is recognizing that actions-communication being considered a specific type of action, and actions always having a communicative component (Winkin 2001) — are embedded in specific situations, which contribute to configure their semantic contents. Actions are always sited, and they aim at specific outcomes, in a given situation. Conversely, actions also contribute to shape situations, as they carry on their own effects. Situations are thus a condition, a dimension, and a product of actions.

Understanding action thus involves delineating how local situations are socially and cognitively constructed. Similar in this to what Dodier (1993, 66) calls a "sociological pragmatics", I propose that this effort involves understanding how social dynamics, in a broad sense (as encompassing cultural, political, and economic phenomena) aggregate and interact locally to frame expectations about/ according to specific circumstances, by conveying meaning from past events and framing anticipations, considering the structuring necessities of unfolding events (Abbott 2016; Bastide 2015a; Tsing 2005). ${ }^{3}$ Contextualizing is thus a matter of relocating the present (unfolding events) in this tensed, multilayered temporality. In this analytical framework, the present thus has a logical precedence over the other time-spaces (past and future) since it is the only possible locus of action and cognitive operations, where past and future are linked according to the requirements of the here and now of social life (Abbott 2016).

Understanding local situations thus involves looking at (1) Current circumstances - how a specific event operates and reconfigures existing institutions and social arrangements, by introducing new stakes; (2) History, as a collection of past, individual and collective experiences, which can be used to attribute meaning to

\footnotetext{
${ }^{2}$ Personal observation, workshop on post-Ebola reorganization, WHO headquarters, Geneva.

${ }^{3}$ Understanding these meanings, expectations and anticipations is critical since they form the base for action.
} 
current circumstances (Abbott 2001, 2016; Schutz 2011); and (3) Anticipationsbased on "social imaginaries" framing the perception of possibilities and probabilities contained in the present (Appadurai 1996, 2013). Thus, for instance, one cannot understand the EVD outbreak in West Africa without clarifying its relation to colonial and postcolonial medical practices across the region; in the same spirit, it is difficult to understand the crisis without looking at prevailing social imaginaries to understand vernacular rationalizations of the event, involving culturally and socially formed expectations; and it is difficult as well to make sense of the situation without looking at how the event reshuffles social arrangements and draws a line between a before and an after (Bensa and Fassin 2002) - as when Ebola intersected with political elections, or with social relations by restricting body contacts or disturbing funeral rituals.

Therefore, I want to use this basic conceptual toolbox to look at each of these different time frames (present/past/anticipations) in order to analyze the logic of action deployed by affected populations. This, in turn, will allow shedding light on the "motives" (Mills 1940) underpinning action courses, thus pointing toward specific forms of rationality. However, I need to stress that my expertise concerns outbreak response rather than local societies and histories; thus, I want to show that, by applying a relevant set of analytical tools, one is able to map out and look for relevant information in any given situation, in a sensitive, meaningful and efficient way, in spite of knowledge gaps regarding local circumstances-social, cultural, political, and economic patterns.

\section{Current Circumstances, Past, Anticipations}

\section{Current Circumstances: Mapping the Stakes}

The EVD outbreak opened a period of high uncertainty. As with every crisis of such scope, deep uncertainties created all kinds of new political, economic or social stakes, and opportunities (Klein 2007). Within affected localities, power relations were reconfigured by the epidemic: for example, some fractions of the people were able to seize working opportunities and contributed to staff the response; local political or moral figures, who were hired in the response to create trust between responders and communities, saw their social prestige increase or erode due to this position (Faye 2015); Ebola became a political stake during parliamentary elections in Liberia (NYT, December 4th, 2014), Guinea (Al Jazeera, October 10th, 2015), ${ }^{4}$ as in the US during 2014 mid-term elections (Politico, October 10 2014; personal interviews at the US CDCs in Atlanta) due to an imported case and the development of a local transmission chain in Dallas. Communicators lamented about what they

\footnotetext{
${ }^{4}$ http://www.aljazeera.com/indepth/features/2015/10/deadly-clashes-flare-guinea-election-151010 132336700.html.
} 
understood as political interferences; they also complained about media coverage, thus effectively ignoring that both politicians and the media conform to logic of actions articulated around different stakes and interests that those regulating public health experts' practices.

Stakes were also high within and among institutions and organizations involved in the response. Indeed, the organization of an emergency response structure had deep effects on organizations' processes, as specific organograms were drafted, put in place and populated to structure the response. Negotiation about appropriate functions and expertise to be involved fostered competition between different departments, and available positions sustained competition between different individuals, within individual organizations. The fact that Bruce Aylward was officially appointed as the head of Ebola response at WHO as late as January 26, 2015, six months after WHO's declaration of Ebola as a Public Health Emergency of International Concern (PHEIC), is a testimony of the intensity of underlying negotiations. In one of our interviews, an informant framed this issue in telling terms: "Ebola makes careers" (personal interview, MSF Swiss member, December 17, 2014).

As in any "humanitarian space" (Hilhorst and Jansen 2010), Ebola also shaped an "arena" (Céfaï 1996) where different stakeholders-national institutions, international organizations, local, and transnational NGOs-competed for different types of resources - to enhance their profile as emergency experts; for funding; in order to increase their authority; to capture existing or emerging fields of action; and so on. For instance, a competition developed around the issue of communication, as prevailing "social mobilization" and "health promotion" techniques failed to convince people to comply with the prescriptions of involved institutions. Social mobilization thus shifted toward "community engagement", that is a more interactional way of negotiating interventions. The opening of this new domain of action drove struggles around the definition of this new, still blurry, field of expertise, both within organizations, as it foreshadowed the reorganization of communication capacities, and at an inter-organization level as it opened a new cluster in emergency response systems, in need of staff and leadership.

Responders usually failed to consider these overlapping dynamics, integral to affected populations and to responding organizations. And, as a consequence, they also failed to recognize that the response itself, as a set of specific practices and interactions, created new social networks and collectives involving both responders and local societies. ${ }^{5}$ Such social interactions and dynamics framed the situations in which individuals and collectives dug into the past to make sense of current circumstances.

\footnotetext{
${ }^{5}$ Considering this, analyzing the response itself as a specific social formation involving and cutting across responders and local populations, with its own social dynamics, would be interesting. Clues to this approach can be found in Ong and Collier (2005).
} 


\section{History, Expectations, Anticipations: Mapping Conflicts}

Among the numerous historical "lineages" (Abbott 2016) which combined to frame Ebola as a public issue in the different countries, let me mention just a few.

First, the legacy of colonial medicine (Anderson 2014; Marks 1997) and the logic of postcolonial global health (King 2002) probably played a significant role in raising people's mistrust while confronting the massive public health enterprise swooping down on them. Historical work has shown, for instance, that colonial public health was not predicated upon the will to better colonized populations' welfare, or only in minor ways. It rather aimed at ensuring the biological well-being of European settlers (Lachenal 2014), at safeguarding the productivity of the local workforce, or at experimenting with hygienist utopias involving, for instance, segregated urban planning, or epidemiological or medical techniques such as mass vaccination against trypanosomiases (Lachenal 2010). In Liberia and Sierra Leone, British colonial medicine did little to better local population's circumstances (Cole 2015). In this context, it is easy to understand that the massive influx of organizations and individuals from advanced industrial countries was met with caution, to say the least.

This kind of reactivation of old, asymmetrical relations of exploitation could only be reinforced by the militarization of the response, with the deployment of the US, British, and French troops and/or logistical capacities in Sierra Leone, Liberia, and Guinea, which gave an obvious neocolonial twist to the intervention, while old colonial powers reinvested past dominions.

It would be useful also to investigate the effects of pharmaceutical companies' dubious practices in the region (Chippaux 2005), which might have further contributed to frame social imaginaries regarding Western medicine and to raise suspicion.

Last, internal tensions within countries also played a major role in complicating the response. Thus, entrenched conflicts between the central government and affected communities, in Guinea, fueled suspicion toward the response as a whole, be it domestic or international, since outsiders were being seen as working with the State, and since the State was often seen as a Trojan horse for foreign interests (Faye 2015).

Anticipations and expectations were thus framed against this backdrop, making people's individual and collective behavior toward the response all the more rational.

\section{Re-assembling Rationality}

Thus, if conflicts and violence arose between affected populations and actors of the response, one of the most striking features of the crisis was the conflict of $r a$ tionalities at play between responders and affected populations. More challenging, misunderstanding arose from the entrenched idea, across response apparatuses that local citizens were acting erratically, irrationally, or at best according to obsolete 
traditional beliefs. Thus, many professionals deployed in the field more or less explicitly relied on sets of binary representations to characterize the relationship between response apparatuses and local populations: Us and Them, cutting-edge science versus traditional healing practices, rationality versus beliefs, expertise versus primitive knowledge, and so on. To explain sometimes violent encounters between intervention teams and affected populations, one of our respondent at WHO thus put forward the cultural violence entrenched in local cultural practices, mentioning cases of cannibalism - a claim which proved untrue. Her own fear was thus predicated upon misleading expectations, themselves related to phantasmagorical lineages and stereotypes. Thus, misaligned expectations due to stereotyping and superficial knowledge prevailed on both sides of the response. Developing a "symmetrical anthropology" (Faye 2015; Latour 1997) of the response would thus have helped debunking mutual stereotypes and relativizing West African people's putative lack of rationality.

Indeed, as some anthropologists have shown, popular resistance to public health interventions surely retained their own rationality (Faye 2015) — a given for any social scientist. In relation to the proposed conceptualization of "context", rationality can be understood as a cognitive path developed by social actors to process the relation between current events, history, and anticipations in order to make sense of the situation and to act consistently. Thus, as it has been clarified in social sciences at least since Weber's seminal delineation between different types of rationality - i.e., value-oriented or means-ends oriented (Weber 2003) - the problem is not to draw a line between rationality and irrationality, but to recover and outline the internal logic of specific forms of social action (Bastide 2015b).

This conceptualization helps understanding why the biomedical logic of the early response in West Africa was met with resistance. If it surely needs to be empirically documented, it is clear that affected populations could only relate to this deployment by referring to the past-hence, the importance of considering the legacy of colonial medicine, the intricacies of postcolonial global health, to reflect on the postcolonial aspect of the response and to consider local political dynamics - to ascribe specific motivations and intentions to the actors of the response, and by drawing anticipations according to this understanding. In this respect, the fear of entrusting one's relatives to medical staff dressed in awe-inspiring Personal Protective Equipment (PPE), knowing that, at the beginning of the crisis, most of these patients would be buried without ever returning to their families, are easily understood. As one of our respondents at the Geneva University Hospital phrased it, this reluctance is very easy to grasp with a simple thought experiment, by transposing the situation in our own countries and families (personal interview, December 19, 2014). However, this individual understanding did not diffuse within collective practices developed across response structures. Furthermore, it is important to stress again that, on the side of responders, social imaginaries about Africa played a symmetrical role to this of local populations' own expectations and anticipations, further blurring the response, as a social relation.

Framing popular behaviors as irrational bore important consequences. Referring to the issue of traditional funerals, a high-risk practice considering that rituals 
involve close contact with highly infectious bodies, M. Osterholm, a prominent US expert on emerging infectious diseases wrote:

Public health workers haven't been able to curtail this traditional practice; it's a challenge that puts religious and cultural beliefs in direct conflict with infection control. (The

Washington Post, August 1st, 2014)

Trying to redress what medical practitioners widely perceived as obsolete, dangerous, and backward beliefs, by means of social mobilization and public marketing, rather than leveraging on this rationality to renegotiate biologically safer funeral practices in ways respectful of and meaningful to affected populations, caused much delays in the response. Indeed, communicators were very slow to understand that, for many, the very real risk associated to the transgression of funeral practices could well exceed the perceived risk of dying from Ebola (Brives et al. 2016). Conflicting definitions of risks were thus at play, between a biomedical risk and a moral risk associated with breaching rituals.

\section{Conceptualizing Populations, Analyzing the Crisis}

The purpose and methods of crisis communication developed at the onset of the outbreak failed to consider these different dimensions. At the same time, however, the fact that emergency response faced different forms of resistance among affected population also stressed the importance of putting professional communication specialists at the forefront of the response. This move was unprecedented in public health. It was the first crisis of this magnitude that saw communicators being embedded in the US CDCs health "swat teams" (Anderson 1994) deployed in the field, at the request of technical teams who had long looked down upon them (personal interview, CDC Headquarter, August 18th, 2015, Atlanta). At WHO as well, communicators quickly gained momentum within the response structure, for the very same reason, since biomedical interventions were often rejected by affected population, a refusal sometimes escalating into violent attacks (see for instance: Afrik.com, February 13th, 2015). Communication was expected to bridge the all too apparent divide between the logic of action enacted by responders, and their perception by affected populations. As a matter of fact, it only brought mixed results. Let me focus on this semi-failure. I will proceed by contrasting the proposed conceptualization of "context" with the tools available to communicators, across organizations, during the EVD outbreak in West Africa. These tools are indeed remarkably standardized and consistent.

When the international response deployed in West Africa, organizations behaved as if they had reached a terra incognita. Ebola was not an expected pathology in this region, and it displayed unusual features such as multiple epidemic locations and its spread to capital cities. In an emergency setting, organizations were usually unable to identify, consider or to tap into available knowledge, including local knowledge and previous scientific surveys, to develop an accurate understanding of 
the situation. ${ }^{6}$ What they usually did, in order to quickly assemble information on the local context, was to run Knowledge, Attitudes, and Practices (KAP) surveys to design "evidence-based" communication strategies. This type of survey, originally developed in the 1950s to measure attitudes and practices with regards to family planning, has gradually become a ubiquitous technique to plan and to measure the outcomes of a broad range of public health interventions in countries in the South. They aim at measuring a population's knowledge, attitudes, and practices around a specific issue, through the use of questionnaires, and to assess the impact of implemented interventions, by being ran at regular intervals. This excerpt from an end of mission report (organization cannot be named for confidentiality reasons) illustrates these following points:

- Analysed an existing KAP survey in [Location name] and integrated findings into communications and social mobilization strategy; and supported and reviewed proposals for two new KAP studies:

a. one in [Location name] to set a baseline for communications and social mobilization work there,

b. and the second a repeat of the one done previously in [Location name] to measure against the existing baseline survey to evaluate the outcomes of communications and social mobilization work there.

KAP surveys thus framed public health interventions throughout the crisis: they acted as a context-making practice, allowing organizations to stabilize an understanding of their field of action; they also played the role of an evaluation device, providing a feedback on the efficacy of implemented interventions. KAP surveys thus made action possible, by generating information, allowing to identify needs and gaps, and to design appropriate strategies. Critically, it allowed gathering data in a speedy way. As such, they proved well fitted to the time-frame of an emergency. And indeed, speed, cost-effectiveness, and the production of seemingly hard data, under the form of statistics, is what makes them popular among health-oriented organizations.

However, this technique suffers from numerous flaws. Let me mention a few, extracted from a paper by Launiala (2009): first, KAP surveys only measure people's biomedical knowledge; as such, they neglect vernacular practices and knowledge about health, diseases, and cure. Moreover, the information they produce is over-reliant on language and formal knowledge, thus neglecting more practical, less formalized types of knowledge. Being framed as standardized questionnaires, they also raise issues in terms of translation and the use of an appropriate language with local populations. Eventually, they rely on personal knowledge, thus individualizing knowledge and practices by abstracting them from their embeddedness in social networks and dynamics.

\footnotetext{
${ }^{6}$ This stresses the issue of knowledge management rather than knowledge production per se. Knowledge was available, but institutions were not able to retrieve it in a timely manner. More than a scientific issue, we are thus faced with an organizational problem.
} 
This conceptual privilege of the individual over collectives is reflected also in available crisis communication guidelines. A look at the latest CDC's Crisis and Emergency Risk Communication guide (CDC 2014), the most comprehensive institutional resource for risk communication in the field of public health emergencies, helps grasp this issue: in the document, public behaviors in health crises are depicted in purely psychological terms, in a chapter entitled: "Psychology of a crisis". The context is reduced to a series of stimuli inducing a narrow variety of psychological states, aroused by specific events, namely: uncertainty; fear, anxiety, and dread; hopelessness and helplessness; denial; panic. These states then translate into a limited a number of behaviors. This model empties social and cultural patterns of all substance, as it draws on very basic versions of behaviorist psychology, typical of the professional literature on risk communication: the link between message production and emission and behavior change is understood in terms of simplistic causal relations. Just as KAP surveys, this model is well fitted to the specific temporality of a crisis as it provides a base for a speedy reaction by allowing to design simple algorithms of the type, in this case, implement that intervention in order to produce the following outcome. In terms of communication, KAP surveys provide the baseline to define the case, under the form of a situational assessment. Once the situation is characterized, it becomes possible to design a specific stimulus, aimed at producing a behavioral twist - the outcome. Another KAP survey then reassesses the situation, by including previous outcomes. Like KAP surveys, these plans are action (rather than knowledge)-oriented; like KAP surveys, they leave "responders" with the feeling of developing evidence-based actions and strategies.

However, as an interviewee at the CDCs rightly underscored, conflicting needs emerge in such a crisis between speed and accuracy of information, and between rendering complexity and the need for operational decision instruments. It is easy to see that, during most crises, the urge for quickly actionable information prevails over the need for depth and precision. KAP surveys can thus be seen as a middle-road in the highly constrained environment of an emergency: it provides speed, actionability, entitlement (they produce the evidences needed for evidencebased interventions). However, they also produce low-quality data. While my conceptualization of the context stresses the need to look at current individual and collective dynamics, in relation to past events and to culturally framed expectations and anticipations, this type of tools shapes the context as a collection of timeless and socially disembedded individual opinions and knowledge. Therefore, the need for speed somehow results in the production of what can be termed, quite paradoxically, a decontextualized contextualization, where individuals are abstracted from their social embeddedness in social networks, in lineages of past events, and in a specific cultural horizon and are reinscribed as simple parameters in the realm of evidence-based interventions.

As a matter of fact, the dramatic emergence of the context as a prominent agent in the crisis underlines the weakness of these models. And institutions and individuals enrolled in the response were ill-equipped to face this challenge, as they lacked appropriate analytical tools to deal with this dimension. Hence, the belated 
and somehow improvised resort to anthropologists when affected populations' resistance derailed the deployment of response systems (see for instance: NPR, September 28, 2014). The current reflection, at WHO, to integrate social scientists within emergency response human resources is a clear recognition of this fact (SciDevNet, April 29, 2015): failing to consider and analyze sociocultural patterns plagued the response and pointed toward the need to shift from quantitative data collection, informed by a reductionist, solipsist behaviorist bias, toward more qualitative, inclusive ethnographic research practices. Of course, behaviors evolved during the crisis, making infection control easier as it unfolded. However, in the absence of reliable data, it is impossible to attribute these changes to implemented communication interventions. Most likely, they are in good part the result of populations' own agency and capacity to draw lessons from their experience in dealing individually and collectively with the crisis.

\section{Conclusion}

In a context of high uncertainty, information is gold; as mentioned in most public health emergency communication plans and guidelines, the first step to be taken during a crisis is to make sense of the situation, in order to establish evidence-based response strategies. Hence, the critical role attributed to situational assessments, and the need for ready-made tools and algorithm-like plans of action: they allow speeding-up the process of data collection, to trigger action, and to orientate the response. However, the EVD episode in West Africa showed that these techniques produce low-quality data, with few remaining relations to the complexity of actual social dynamics. It is partly when anthropologists were brought into the response structure that relevant issues could be mapped and addressed. Yet, many responders expressed frustration with the lengthy temporality required by the logic of ethnographic inquiry. Thus, we witness a two-fold movement taking place as after-action evaluations are being developed: first, anthropological consultant firms and anthropological staff in organizations advocate the development of a new field of "emergency anthropology"; their first requirement is to develop methodologies consistent with the high pace of a crisis, combining the production of accurate and actionable knowledge, in a speedy way. However, this tendency is not without raising concerns among more critical, academic anthropologists. ${ }^{7}$ Second, organizations such as WHO are thinking about shifting their recruitment policy in the area of communication staff, by hiring less public communication specialists in favor of a more social science-oriented workforce. It remains to be seen, however, whether sound survey methodologies are compatible or not with the time compression that characterizes emergency situations. What can be said, at least, is that, after all, much

\footnotetext{
${ }^{7}$ This is somehow a classical dynamic of professionalization, well documented in the sociological archive.
} 
time was lost, in this episode, by not resorting to these qualitative survey techniques: speeding-up action based on too fragile knowledge is a risky business.

\section{References}

Abbott, A. D. (2001). Time matters: On theory and method. Chicago, Ill.: University of Chicago Press.

Abbott, A. D. (2016). Processual sociology. Chicago, Ill.: University of Chicago Press.

Anderson, C. (1994). Sentinel health unit surveillance system. The Canadian Journal of Infectious Diseases, 5(5), 207-209.

Anderson, W. (2014). Making Global Health History: The Postcolonial Worldliness of Biomedicine. Social History of Medicine, hkt126. https://doi.org/10.1093/shm/hkt126.

Appadurai, A. (1996). Modernity at large: Cultural dimensions of globalization. Minneapolis, MN: University of Minnesota Press.

Appadurai, A. (2013). The future as cultural fact: Essays on the global condition (Vol. 1-1). London, New York: Verso.

Bastide, L. (2015a). Habiter le transnational: Espace, travail et migration entre Java. Lyon, ENS éditions: Kuala Lumpur and Singapore.

Bastide, L. (2015b). Faith and uncertainty: Migrants' journeys between Indonesia, Malaysia and Singapore. Health, Risk \& Society, 17(3-4), 226-245. https://doi.org/10.1080/13698575.2015. 1071786.

Bensa, A., \& Fassin, E. (2002). Les sciences sociales face à l'événement. Terrain. Revue d'ethnologie de l'Europe, 38, 5-20. https://doi.org/10.4000/terrain.1888.

Brives, C., Marcis, F. L., \& Sanabria, E. (2016). What's in a context? tenses and tensions in evidence-based medicine. Medical Anthropology, 35(5), 369-376. https://doi.org/10.1080/ 01459740.2016.1160089.

Burawoy, M. (1979). Manufacturing consent: Changes in the labor process under monopoly capitalism. Chicago, Ill.: University of Chicago Press.

CDC (2014) Crisis Emergency Risk Communication, US Centers for Disease Control and Prevention, Atlanta, 2014

Céfaï, D. (1996). La construction des problèmes publics. Définitions de situations dans des arènes publiques. Réseaux, 14(75), 43-66. https://doi.org/10.3406/reso.1996.3684.

Chippaux, J. P. (2005). L'Afrique, cobaye de Big Pharma. (2005, juin 1). Le Monde diplomatique. https://www.monde-diplomatique.fr/2005/06/CHIPPAUX/12513. Accessed on March 17, 2016.

Cole, F. (2015). Sanitation, disease and public health in Sierra Leone, West Africa, 1895-1922: Case failure of British colonial health policy. The Journal of Imperial and Commonwealth History, 43(2), 238-266. https://doi.org/10.1080/03086534.2014.974901.

Dodier, N. (1993). Les appuis conventionnels de l'action. Eléments de pragmatique sociologique. Réseaux, 11(62), 63-85.

Faye, S. L. (2015). L' «exceptionnalité » d'Ebola et les «réticences »populaires en Guinée-Conakry. Réflexions à partir d'une approche d'anthropologie symétrique. Anthropologie \& Santé. Revue internationale francophone d'anthropologie de la santé, (11). https://doi.org/10.4000/anthropologiesante.1796.

Fribault, M. (2015). Ebola en Guinée: Violences historiques et régimes de doute. Anthropologie \& Santé. Revue internationale francophone d'anthropologie de la santé, (11). https://doi.org/10. 4000/anthropologiesante.1761.

Hilhorst, D., \& Jansen, B. J. (2010). Humanitarian space as arena: A perspective on the everyday politics of aid. Development and Change, 41(6), 1117-1139. https://doi.org/10.1111/j.14677660.2010.01673.x. 
Jakobson, R. (1960). Closing statement: Linguistics and poetics. In T. A. Sebeok (Ed.), Style in language (pp. 350-377). Cambridge, Mass: MIT Press.

King, N. B. (2002). Security, disease, commerce ideologies of postcolonial global health. Social Studies of Science, 32(5-6), 763-789. https://doi.org/10.1177/030631270203200507.

Klein, N. (2007). The shock doctrine: The rise of disaster capitalism. London: Penguin.

Lachenal, G. (2010). Le médecin qui voulut être roi. Annales. Histoire, Sciences Sociales, 65e année(1), 121-156.

Lachenal, G. (2014). Le médicament qui devait sauver l'Afrique: un scandale pharmaceutique aux colonies. Paris: la Découverte.

Latour, B. (1997). Nous n'avons jamais été modernes: essai d'anthropologie symétrique. Paris: La Découverte.

Launiala, A. (2009). How much can a KAP survey tell us about people's knowledge, attitudes and practices? Some observations from medical anthropology research on malaria in pregnancy in Malawi. Anthropology Matters, 11(1). http://anthropologymatters.com/index.php/anth_ matters/article/view/31. Accessed on March 25, 2016.

Malagardis, M. (2014, Septembre 20). Entre fantasmes et sorcellerie, Ebola tue aussi par l'ignorance; En Guinée, une délégation de prévention a été assassinée à la machette. Le Temps. https://www.lexisnexis.com/uk/nexis/docview/getDocForCuiReq?Ini=5D5T-0151JBSTY1NV\&csi=257973\&oc=00240\&perma=true. Accessed on September 22, 2014.

Marks, S. (1997). What is colonial about colonial medicine? And what has happened to imperialism and health? Social History of Medicine, 2, 205-219.

Mills, C. W. (1940). Situated actions and vocabularies of motive. American Sociological Review, 5 (6), 904-913. https://doi.org/10.2307/2084524.

Moulin, A. M. (2015). L'anthropologie au défi de l'Ebola. Anthropologie \& Santé. Revue internationale francophone d'anthropologie de la santé, (11). https://doi.org/10.4000/ anthropologiesante.1954.

Ong, A., \& Collier, S. J. (2005). Global assemblages: Technology, politics, and ethics as anthropological problems. Malden: Blackwell.

Schutz, A. (2011). Phenomenology and the social sciences. In L. Embree (Ed.), Collected papers $V$. Berlin: Springer.

Simmel, G. (2007). The stranger. In C. Calhoun, J. Gerteis, J. Gerteis, J. Moody, S. Pfaff, \& V. Indermohan (Eds.), Classical sociological theory (pp. 295-299). Wiley-Blackwell.

Tsing, A. L. (2005). Friction: An ethnography of global connection. Princeton, NJ: Princeton University Press.

Weber, M. (2003). Economie et société, tome 1 : Les Catégories de la sociologie. Pocket.

Winkin, Y. (2001). Anthropologie de la communication: de la théorie au terrain. Seuil: De Boeck \& Larcier/Paris.

Open Access This chapter is licensed under the terms of the Creative Commons Attribution 4.0 International License (http://creativecommons.org/licenses/by/4.0/), which permits use, sharing, adaptation, distribution and reproduction in any medium or format, as long as you give appropriate credit to the original author(s) and the source, provide a link to the Creative Commons license and indicate if changes were made.

The images or other third party material in this chapter are included in the chapter's Creative Commons license, unless indicated otherwise in a credit line to the material. If material is not included in the chapter's Creative Commons license and your intended use is not permitted by statutory regulation or exceeds the permitted use, you will need to obtain permission directly from the copyright holder.

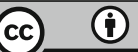

